\title{
Size Effect on Thermal Shock Behavior of an Alumina
}

\author{
Chih-Kuang LIN and Tsung-Chih KUO \\ Department of Mechanical Engineering, National Central University, Chung-Li 32054, Taiwan, R.O.C.
}

\author{
アルミナの熱衝撃挙動に及ぼす寸法効果 \\ 林 志光・郭 宗志 \\ 國立中央大學工學部機械工學科，32054 中華民國台灣省中壢市
}

\begin{abstract}
This study investigated the degradation in mechanical properties of an alumina subjected to thermal shock loading by systematic experiments on bend-bar specimens of two sizes, $3 \times 4 \times 45 \mathrm{~mm}$ and $9 \times 12 \times 45 \mathrm{~mm}$. Thermal loading was applied by water-quench method with several well defined temperature differences. Critical temperature difference $\left(\Delta T_{\mathrm{c}}\right)$ was defined as the lowest applied temperature difference above which a loss in flexure strength occurred. $\Delta T_{\mathrm{c}}$ values for the large and small specimens were found to be 175 and $200{ }^{\circ} \mathrm{C}$, respectively. The reduction in thermal shock resistance with increasing sample size can be well described by the thermal elastic and fracture energy theories. However, if the size effect on the initial, unshocked fracture strength is considered, the size effect on the transport of heat during quench test might play a less important role in reducing the thermal shock resistance of large specimen.
\end{abstract}

[Received February 26, 1997; Accepted September 19, 1997]

Key-words : Thermal shock, Size effect, Fracture strength, Alumina

\section{Introduction}

The thermal shock resistance of ceramics is one of the most important criteria for the use of ceramics in the environments of rapidly changing temperatures or severe thermal gradients. Obvious examples include turbines, heat exchanger components and cutting tools. The thermal shock behavior of ceramics has been studied extensively (e.g., Refs. ${ }^{1)-8)}$ ). The important variables which affect thermal shock resistance are material's strength, fracture energy, elastic modulus, thermal expansion, conductivity, surface heat condition, and specimen size and geometry. ${ }^{1)-9)} \mathrm{A}$ common laboratory method to determine thermal shock resistance of ceramics is the quench experiment, where heated samples are quenched into a coolant, generally water, and the retained strength after quenching is measured in bending. When the temperature difference is sufficient to cause a loss in strength, this temperature difference represents the critical temperature drop, $\Delta T_{\mathrm{c}}$. The thermal shock resistance becomes greater as $\Delta T_{\mathrm{c}}$ increases.

The importance of specimen size and heat transfer rate is reflected in the general form of the equation for the critical temperature difference where the thermal stress $\sigma_{t}$ is then equated to the material's unshocked, originate fracture strength $\sigma_{f} \cdot{ }^{11,9)}$

$$
\sigma_{\mathrm{t}}=\alpha E \Delta T_{\mathrm{c}} /[(1-v) f(\beta)]=\sigma_{\mathrm{f}}
$$

Rearrangement of Eq. (1) yields

$$
\Delta T_{\mathrm{c}}=\left[\sigma_{\mathrm{f}}(1-v) / \alpha E\right] f(\beta)
$$

where $\alpha$ is the linear thermal expansion coefficient, $E$ is the Young's modulus, $v$ is the Poisson's ratio, $f$ is a function of the Biot modulus, $\beta=a h / k$, with $h$ the surface heat transfer coefficient (surface conductance), $k$ the material's thermal conductivity, and $a$ the characteristic heat transfer length. The characteristic heat transfer length, $a$, is usually taken as the ratio the specimen volume to the surface area $(V / A)$ or a multiple of this length, or the shortest heat transfer length of the specimen which is the thickness or diameter of the bend-bar.

The effects of the quenching conditions on the thermal shock resistance can be reflected by the functional dependence on the Biot modulus term, $\beta=a h / k$ in Eqs. (1) and $(2) .{ }^{6), 9)}$ Both the temperature and stress gradients are reduced with increasing material's thermal conductivity due to the rapid transport of heat. Similarly, decreasing the specimen size will result in smaller temperature and stress gradients as the available heat is more rapidly conducted to the surface and transferred to the quenching media. Smaller temperature and stress gradients can also be expected for the quench media with a lower surface heat transfer coefficient as a result of a lower rate of heat transfer from the specimen.

The effect of specimen size on the thermal shock resistance in ceramics has been evaluated by a few studies. 2),4)-6),8) The size effect on thermal shock resistance observed in those studies were interpreted only in terms of the size effect on the heat change rates. It was generally concluded that the $\Delta T_{\mathrm{c}}$ values for a given material will decrease and then reach or approach constant value with increase in sample thickness. ${ }^{5), 6)}$ However, the role of size effect on the unshocked, originate fracture strength in influencing the thermal shock resistance of ceramic has never been considered. The present study sought to examine the effect of specimen size on the thermal shock resistance of an alumina. The emphasis here is on the importance of size effect on the unshocked, originate fracture strength in determining the $\Delta T_{\mathrm{c}}$ value.

\section{Experimental procedure}

The material selected for the current study is a commercial alumina (Aucera Technology Co., Taoyuan, Taiwan). The average grain size is about $12 \mu \mathrm{m}$ with a density of $3.90 \mathrm{~g} / \mathrm{cm}^{3}$. The major impurity in this nominally $99.5 \%$ pure alumina is $\mathrm{MgO}$. Bend-bar specimens with dimensions of two sizes, $3 \times 4 \times 45 \mathrm{~mm}$ (small) and $9 \times 12 \times 45 \mathrm{~mm}$ (large), were diamond-machined from sintered rectangular bars. The surfaces of each specimen were ground along its length with 300-grit diamond wheels. The four long edges of each specimen were chamfered to avoid premature fracture due to stress concentration during flexural strength test. The dimensions of the small specimen were selected as per ASTM Standard C1161 for measuring flexural strength of ceramic at room temperature. The large specimens were made for direct comparison to study the size sensitivity of thermal shock resistance. 
Thermal shock tests were conducted by water-quench method. Specimens were heated at a rate of $15^{\circ} \mathrm{C} / \mathrm{min}$ to specific higher temperatures in an air furnace and dropped by free fall into a quench bath that contained $30 \mathrm{l}$ of roomtemperature water $\left(25^{\circ} \mathrm{C}\right)$. The distance of dropping path was $\sim 0.5 \mathrm{~m}$ and the water bath was $0.25 \mathrm{~m}$ deep. The water bath did not show any measurable change in temperature during quenching. In all cases the specimens were kept in the furnace for at least $30 \mathrm{~min}$ to assure temperature uniformity before quenching. The quenching temperature difference, $\Delta T$, ranged from 100 to $500^{\circ} \mathrm{C}$ and 100 to $300^{\circ} \mathrm{C}$ for small and large specimens, respectively, to determine the critical temperature difference, $\Delta T_{\mathrm{c}}$. The flexural strengths of both large and small specimens were measured in as-received condition and after quench of various $\Delta T$ conditions. The four-point flexure tests were conducted with a support span of $40 \mathrm{~mm}$ and a load span of $20 \mathrm{~mm}$ using a closed-loop servohydraulic testing machine. Photographs were taken of selected large and small specimens after dyeing the surfaces with a red dye penetrant for various $\Delta T$ conditions to examine the cracking patterns induced by thermal shock.

\section{Results and discussion}

\subsection{Determination of $\Delta T_{c}$}

Figure 1 shows the results of the room-temperature, retained flexure strength testing of small specimens subjected to $\Delta T$ of 100 to $500^{\circ} \mathrm{C}$. The strength data for asreceived, unshocked condition were also plotted in Fig. 1 as $\Delta T=0^{\circ} \mathrm{C}$. Each data point represents a single specimen for that particular quenching condition. Up to $\Delta T=200^{\circ} \mathrm{C}$, flexure strength is not affected. The small specimens exhibited a sudden reduction in retained strength with $\Delta T>200^{\circ} \mathrm{C}$. At $\Delta T=200^{\circ} \mathrm{C}$, four of the ten specimens tested exhibited no change in retained strength while four of the rest six specimens did show a significant reduction in retained strength. The average strength value of these four weakest specimens shocked at $\Delta T=200^{\circ} \mathrm{C}$ is about $60 \%$ of that for as-received, unshocked specimens. Therefore, the critical quench temperature difference for small specimen is defined as $\Delta T_{\mathrm{c}}=200^{\circ} \mathrm{C}$. This method of defining the $\Delta T_{\mathrm{c}}$ value was similar to that used in previous work. ${ }^{1)-4)}$ When $\Delta T$ just exceeds $\Delta T_{\mathrm{c}}$, there is a plateau region of retained strength up to $\Delta T=300^{\circ} \mathrm{C}$. Further increases of $\Delta T$ over $300^{\circ} \mathrm{C}$ result in diminishing retained strength. This shape of thermal shock quench curve has been explained by Hasselman. ${ }^{1)}$

Hasselman $^{1)}$ modeled the thermal shock behavior of a rigid constrained flat plate containing a uniform distribution of microcracks. Uniform cooling was assumed and the

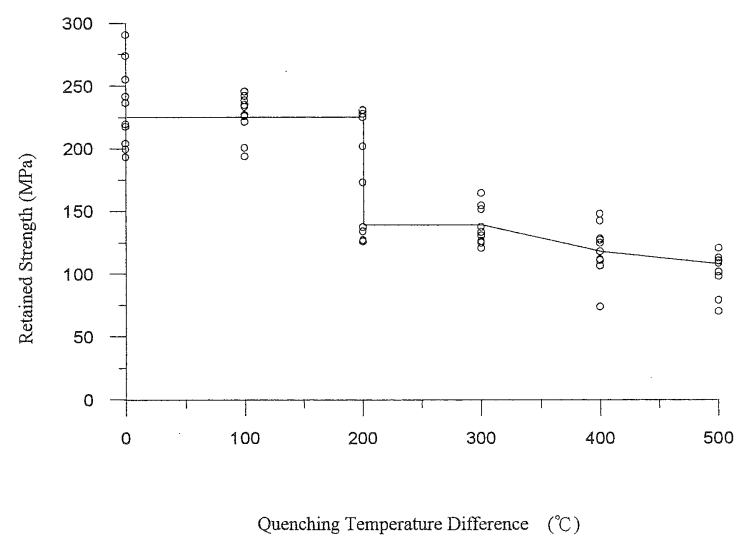

Fig. 1. Relationship between retained strength and temperature difference for small specimens.

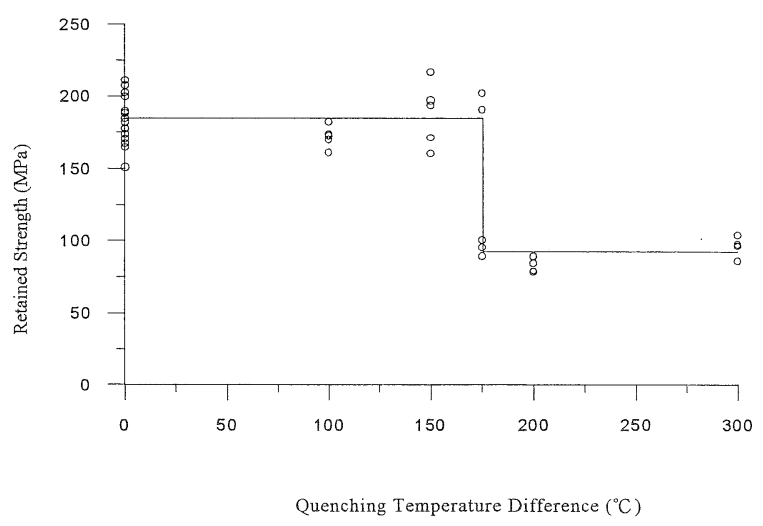

Fig. 2. Relationship between retained strength and temperature difference for large specimens.

Griffith criterion for unstable crack growth was used to define the $\Delta T_{\mathrm{c}}$. Hasselman normalized the $\Delta T_{\mathrm{c}}$ with respect to the thermal expansion coefficient, Young's modulus, and the surface energy of the material and plotted this versus the crack length. Hasselman showed that a material containing short cracks, $l_{0}$, much smaller than a characteristic length, $l_{\mathrm{f}}$, would show a drastic strength drop at $\Delta T_{\mathrm{c}}$ due to the released elastic energy being converted into kinetic energy. For quenches above $\Delta T_{\mathrm{c}}$, but below $\Delta T_{\mathrm{c}}{ }^{\prime}$, the cracks would be subcritical and the strength after thermal shock should thus be independent of the severity of the thermal shock in this region. Above $\Delta T_{\mathrm{c}}{ }^{\prime}$ the strength after thermal shock would gradually decrease. Based on this model, the value of $\Delta T_{\mathrm{c}}$ for small specimen tested is equal to $200^{\circ} \mathrm{C}$ while the value of $\Delta T_{\mathrm{c}}^{\prime}$ is between 300 and $400^{\circ} \mathrm{C}$ as no further tests were conducted between them.

The thermal shock testing results for large specimens are shown in Fig. 2. The critical temperature difference for large specimen can be determined as $\Delta T_{\mathrm{c}}=175^{\circ} \mathrm{C}$, as a sudden drop in the retained strength for large specimen occurs at $\Delta T=175^{\circ} \mathrm{C}$ in that 3 of 5 specimens exhibited significant drop in retained strength. The reduced retained strength for $\Delta T>175^{\circ} \mathrm{C}$ did not significantly change up to $\Delta T=300^{\circ} \mathrm{C}$ and this low value is about $50 \%$ of the average strength value for as-received large specimens. Due to the smaller range of $\Delta T$ applied to the large specimens, the value of $\Delta T_{\mathrm{c}}^{\prime}$ can not be determined from the limited data. However, the smaller value of $\Delta T_{\mathrm{c}}$ obtained for large specimen did indicate the existence of size sensitivity of thermal shock resistance for selected alumina. The specimen size effect on the thermal shock resistance behavior will be further discussed in a following section.

3.2 Cracking patterns in thermal-shocked specimens

The strength results shown in Figs. 1 and 2 are complemented by optical micrographs of the thermal-shocked surface after highlighting the surface crack patterns with a dye penetrant. Examples of such surfaces are shown in Figs. 3 and 4. In Fig. 3 for small specimens, it reveals no surface cracks for $\Delta T<\Delta T_{\mathrm{c}}$, whereas at $\Delta T_{\mathrm{c}}=200^{\circ} \mathrm{C}$ single deep cracks appear for small specimens. With increasing $\Delta T$ above $\Delta T_{\mathrm{c}}$ the crack density on the surface increases. At $\Delta T=300$ to $500^{\circ} \mathrm{C}$ the cracks are more profuse in that lots of small cracks connect with each other and completely traverse the surface. Two small specimens (Nos. 206 and 208) quenched at $\Delta T_{\mathrm{c}}=200^{\circ} \mathrm{C}$ were shown in Fig. 3 . Both specimens indicated an existence of longitudinal surface cracks whereas transverse cracks were only present in specimen No. 208. Here, the longitudinal crack represents the crack aligned parallel to the specimen length, whereas the transverse crack indicates the crack aligned normal to 

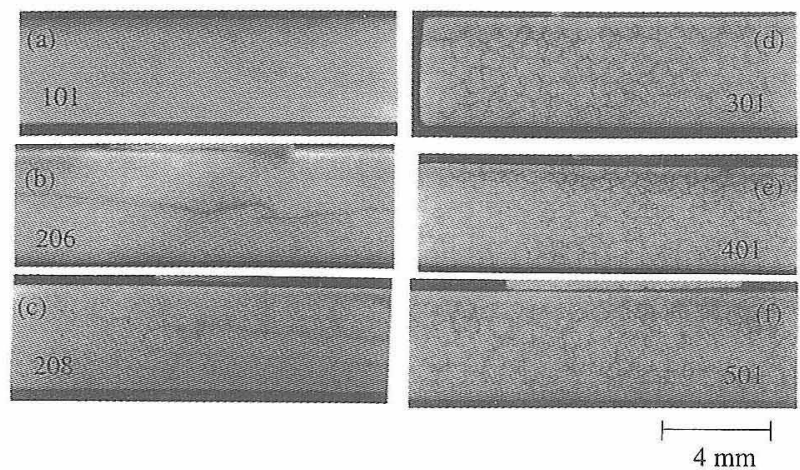

Fig. 3. Surface crack patterns of small specimens subject to thermal shock at several temperature differences: (a) $\Delta T=100^{\circ} \mathrm{C}$, (b) $\Delta T=200^{\circ} \mathrm{C}$, (c) $\Delta T=200^{\circ} \mathrm{C}$, (d) $\Delta T=300^{\circ} \mathrm{C}$, (e) $\Delta T=400^{\circ} \mathrm{C}$, and (f) $\triangle T=500^{\circ} \mathrm{C}$

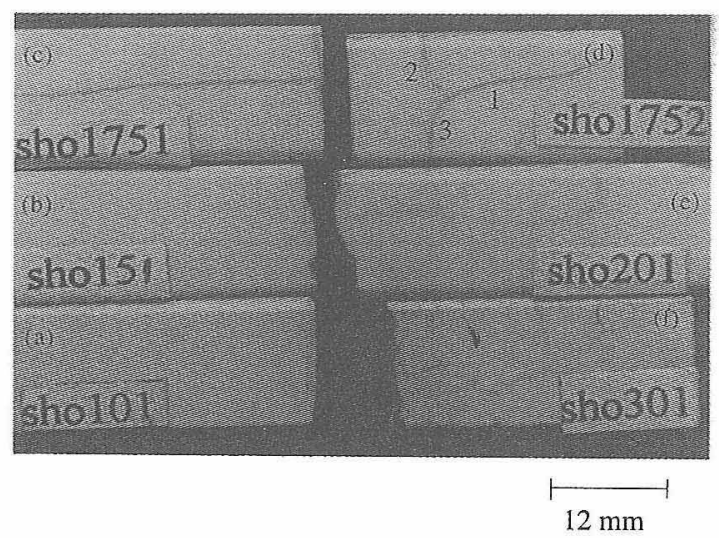

Fig. 4. Surface crack patterns of large specimens subject to thermal shock at several temperature differences: (a) $\Delta T=100^{\circ} \mathrm{C}$, (b) $\Delta T=150^{\circ} \mathrm{C}$, (c) $\Delta T=175^{\circ} \mathrm{C}$, (d) $\Delta T=175^{\circ} \mathrm{C}$, (e) $\Delta T=200^{\circ} \mathrm{C}$, and (f) $\Delta T=300^{\circ} \mathrm{C}$

the specimen length. These cracking patterns agreed well with the results of retained strength measurement. The retained strength value for specimen No. 206 is $227 \mathrm{MPa}$ which is about the same as that of as-received specimen. However, specimen No. 208 exhibited a retained strength value of $134 \mathrm{MPa}$ which represents the significantly reduced value for small specimen subjected to $\Delta T_{c}>200^{\circ} \mathrm{C}$. An important implication obtained from such cracking observation is that the sizes of transverse cracks control the retained strength. Therefore, the invariability of the retained strength with respect to $\Delta T$ indicates that the sizes of strength-controlling transverse cracks remain unchanged up to $\Delta T_{\mathrm{c}}=200^{\circ} \mathrm{C}$.

Similar cracking pattern was observed for large specimens as shown in Fig. 4. No surface cracking was detected for $\Delta T<\Delta T_{\mathrm{c}}$. Two large specimens (Nos. 1751 and $1752(\mathrm{c}),(\mathrm{d}))$ quenched at $\Delta T_{\mathrm{c}}=175^{\circ} \mathrm{C}$ were present in Fig. 4. The retained strength value for specimen No. 1751 with a longitudinal crack present is $202 \mathrm{MPa}$ whereas it is $100 \mathrm{MPa}$ for specimen No. 1752 with existence of both longitudinal and transverse cracks. This further supports that for the given specimen geometry, the transverse thermal stress during quenching is much greater than the longitudinal thermal stress as longitudinal surface crack is easier to initiate than transverse surface crack.

Thermal shocking would give rise to the largest tensile stress at the surface during the water quench for the given specimen geometry and this tensile stress would decay with depth and reach the maximum compressive stress at the center of the specimen. ${ }^{10)}$ At the threshold of cracking, at $\Delta T=\Delta T_{\mathrm{c}}$, the temperature difference in quench is just high enough to activate the largest of the pre-existing surface flaws such that only a little amount of cracking was observed as shown in Figs. 3(b) 'and (c), and Figs. 4(c) and (d). In order to observe the penetration depth of the cracks, the transverse cracks marked by the number labels 2 and 3 in Fig. 4(d) were selected and cut along the specimen length direction for cross-sectional observation. As shown in Fig. 5, these cross-sectional views indicate the thermalshock induced cracks initiated from the surface and penetrated roughly one-quarter of the distance between the surface and center. This penetrating depth is likely just past the boundary between the tensile and compressive stress regions in the specimen similarly as reported in the work of Davidge and Tappin. ${ }^{10)}$ With larger $\Delta T>\Delta T_{\mathrm{c}}$, as shown in Figs. $3(\mathrm{~d})-(\mathrm{f})$ and Figs. $4(\mathrm{e})-(\mathrm{f})$, the number of thermal-shock induced cracks was increased but the depth of penetration was about the same as that shown in Fig. 5 . The increase in the number of surface cracks for $\Delta T>\Delta T_{\mathrm{c}}$ means smaller pre-existing surface flaws in addition to the largest ones were activated during thermal shocking. ${ }^{10)}$ The higher the value of $\Delta T$, the smaller are the pre-existing flaws can be induced to grow into cracks. ${ }^{10)}$

\subsection{Sensitivity of $\Delta T_{c}$ to specimen size}

In the current study, specimen size (thickness and width) had an influence on the critical temperature difference, as the $\Delta T_{\mathrm{c}}$ values decreased from 200 to $175^{\circ} \mathrm{C}$ with an increase in both thickness and width by three times. Whether this reduction in $\Delta T_{\mathrm{c}}$ is due to the reduction in initial strength or/and thermal shock resistance for large specimens needs to be clarified. The sensitivity of $\Delta T_{\mathrm{c}}$ to specimen size is often approximated by a linear functional dependence as follows: ${ }^{5), 9)}$

$$
\begin{gathered}
\Delta T_{\mathrm{c}}=\left[\sigma_{\mathrm{f}}(1-v) / \alpha E\right](A+B k / a h) \\
\text { for } \beta<5
\end{gathered}
$$

where $A$ and $B$ are constant. Equation (3) was obtained from Eq. (2) with the substitution of $f(\beta)=A+B / \beta$, as usually observed for ceramics in the small $\beta$ region.5) However, the $\Delta T_{\mathrm{c}}$ value is independent of the characteristic length for very large specimens $(\beta>100) .{ }^{5)}$ An exponential term is added to the linear function for the transition region
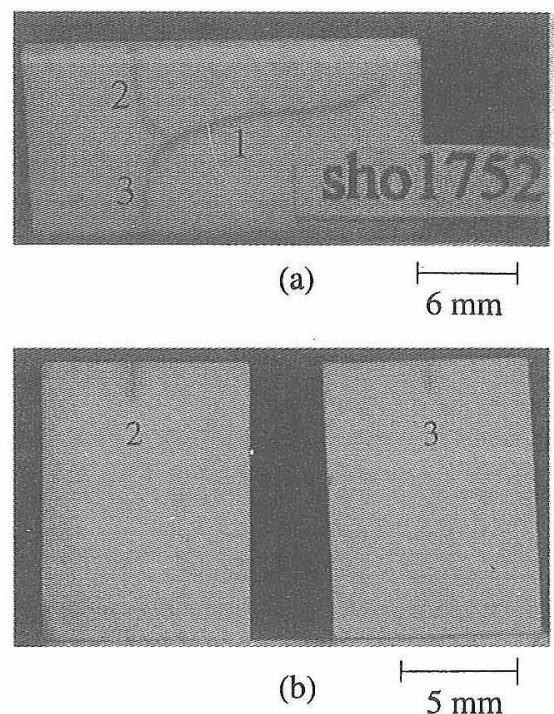

Fig. 5. Crack pattern of a large specimen subject to thermal shock at $\Delta T_{\mathrm{c}}=175^{\circ} \mathrm{C}$ : (a) top view of outersurface with number label 1 as the longitudinal crack and 2 and 3 as the transverse cracks and (b) cross-sectional views of transverse cracks 2 and 3 in (a). 
of $\beta$ value between these two branches. ${ }^{6)}$ This linear function would be applied to analyze the size effect on the thermal shock behavior for selected alumina. A plot of $\Delta T_{\mathrm{c}}$ versus the characteristic length, $a$, should give a linear dependence, if $h$ and $k$ are constants and the effect of specimen size on $\sigma_{\mathrm{f}}$ is assumed to be negligible.

Figure 6 shows the size dependence of thermal shock behavior for alumina ceramics from other studies ${ }^{2,4), 6)}$ and the present work. It is obvious that $\Delta T_{\mathrm{c}}$ decreases with increasing characteristic length for selected alumina ceramics. In particular, the data points generated in the current study together with those from Gupta ${ }^{4}$ lie within a band that may be characterized by the solid straight line implying the smaller $\beta$ values for the given testing conditions. Data from Hasselman's study ${ }^{2)}$ can be fitted by another straight line. However, data from the study of Becher and Warwick ${ }^{6}$ may be better fitted by an exponential function indicating the higher $\beta$ values. The different slopes and intercepts observed for several kinds of alumina reflect the differences in material characteristics and testing conditions including specimen geometry and preparation, quenching media and environment. As is obvious from Eq. (3), the slope is proportional to the term $B \sigma_{\mathrm{f}}(1-v) k / E \alpha h$. Therefore, the existence of linear functional relation between $\Delta T_{\mathrm{c}}$ and $a$ is based on the assumption that the fracture strength $\sigma_{f}$ is independent of specimen size. However, this might not be true for ceramics, whose strength varies with specimen size and is generally predicted by the Weibull theory (e.g., Ref. 11)) for a given material despite identical processing conditions. Therefore, the data presented in Fig. 6 needs to be reinterpreted with consideration of the difference in fracture strength for various specimen sizes.

For materials obeying the Weibull distribution, the size effect on the fracture strength in four-point bending between large and small specimens can be obtained as follows: ${ }^{11}$

$$
\frac{\sigma_{\mathrm{f} \text { large }}}{\sigma_{\mathrm{f}, \mathrm{small}}}=\left(\frac{S_{\text {small }}}{S_{\text {large }}}\right)^{1 / m}
$$

where $\sigma_{f}$ is the mean fracture strength, $m$ is the Weibull modulus, and $S$ is the surface area on the tensile surface between the two inner loading points. In Eq. (4) effective stressed area is used because the thermal-shock induced cracks initiated from the outersurface of the specimen as supported in the cracking pattern observation. This ther-

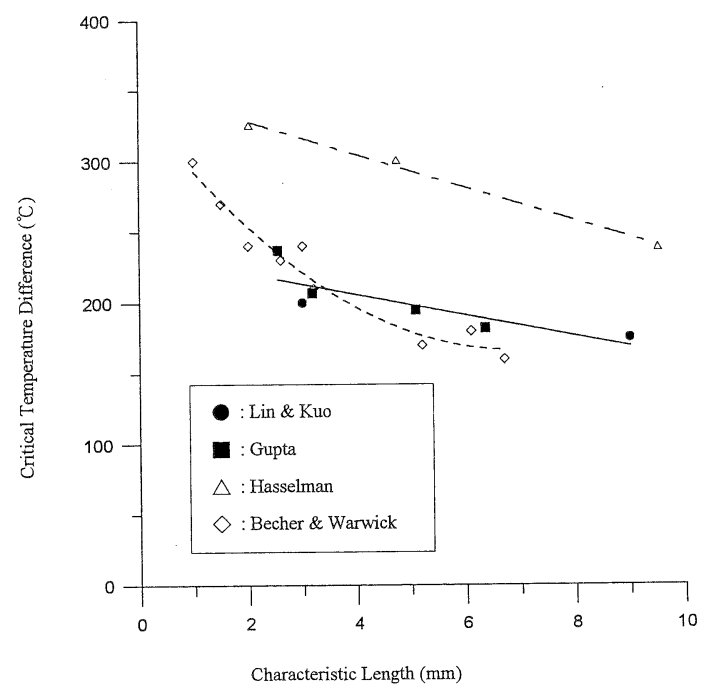

Fig. 6. $\Delta T_{\mathrm{c}}$ versus $(a)$ for various alumina ceramics. mal-shock induced surface cracking would control the flexural strength value in four-point bending measurement. In this regard, Eq. (4) will be used to account for the size effect on the fracture strength for the current study. The relationship between the mean flexural strength, $\sigma_{\mathrm{f}}$, and specimen size in Eq. (4) is actually induced from the following equation ${ }^{11)}$ developed by Weibull analysis:

$$
\sigma_{\mathrm{f}}=\sigma_{0} S^{-1 / m}\left(\frac{1}{m} !\right)
$$

where $\sigma_{0}$ is a scale parameter and the exclamation mark denotes the factorial function. Substituting Eq. (5) into Eq. (3) yields

$$
\begin{aligned}
\Delta T_{\mathrm{c}}= & {\left[\sigma_{\mathrm{o}} S^{-1 / m}\left(\frac{1}{m} !\right)(1-v) / \alpha E\right](A+B k / a h) } \\
& \text { for } \beta<5
\end{aligned}
$$

Equation (6) indicates that the linear functional dependence of $\Delta T_{\mathrm{c}}$ on the characteristic length, $a$, might be no longer true as $S$ is also a function of the characteristic length $a$. Therefore, the sensitivity of $\Delta T_{\mathrm{c}}$ to specimen size is more complicated than that shown in Eq. (3) and should be considered in two parts. The first part relates to the variation of fracture strength due to the change of specimen size as shown in the term $S^{-1 / m}$ of Eq. (6). The second term in Eq. (6), $(A+B k / a h)$, reflects the effect of specimen size on the heat transfer conditions. In order to examine the effect of the second part alone, Eqs. (3) and (6) can be rearranged as

$$
\begin{aligned}
\left(\Delta T_{\mathrm{c}} / \sigma_{\mathrm{f}}\right) & =\left(\Delta T_{\mathrm{c}} / \sigma_{0} S^{-1 / m}\left(\frac{1}{m} !\right)\right) \\
& =[(1-v) / \alpha E](A+B k / a h) \quad \text { for } \beta<5
\end{aligned}
$$

A plot of the value of $\left(\Delta T_{\mathrm{c}} / \sigma_{\mathrm{f}}\right)$ versus the characteristic length $(a)$ should give a linear dependence, if $h$ and $k$ are constant.

A replot of the data presented in Fig. 6 with $\left(\Delta T_{\mathrm{c}} / \sigma_{\mathrm{f}}\right)$ versus $(a)$ is shown in Fig. 7. The data of the study by Becher and Warwick ${ }^{6}$ were not present in Fig. 7 due to lack of the information on the initial, unshocked fracture strength values. In this figure, two different types of linear functional dependence were observed for selected alumina ceramics. Data generated by Hasselman ${ }^{2)}$ showed that the value of $\left(\Delta T_{\mathrm{c}} / \sigma_{\mathrm{f}}\right)$ decreases with increasing specimen size. This is similar to the trend observed in Fig. 6 which can be attributed to the negligible difference in fracture strength for various-sized specimens in Hasselman's study. ${ }^{2)}$

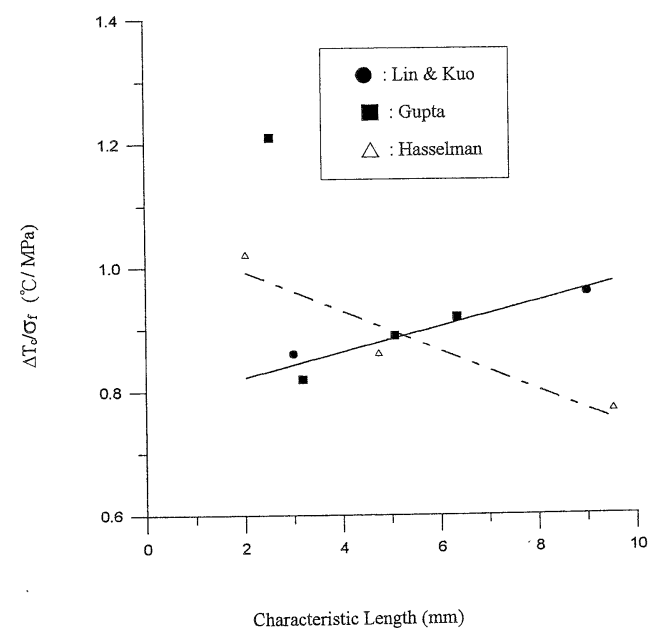

Fig. 7. $\left(\Delta T_{\mathrm{c}} / \sigma_{\mathrm{f}}\right)$ versus $(a)$ for various alumina ceramics. 
Therefore, the observed decrease in $\Delta T_{\mathrm{c}}$ with increasing specimen size for Hasselman's data is indeed due to the size effect on the heat transfer conditions. However, the data from the current study and Gupta's study ${ }^{4}$ except the smallest size exhibit an inverse trend; i.e., the value of $\left(\Delta T_{\mathrm{c}} / \sigma_{\mathrm{f}}\right)$ increases with increasing specimen size. This implies that the reduction in the observed critical temperature difference is mostly attributed to the reduction of unshocked, originate fracture strength as specimen size increases. The odd behavior shown by the data point corresponding to the smallest specimen size in Gupta's results can be explained by its exceptionally low fracture strength as compared to the other three larger specimens whose fracture strengths did exhibit a decreasing trend with increasing size. In the current study, the initial, unshocked fracture strength was reduced $22 \%$ as the specimen width and thickness were both increased by three times. Therefore, the size effect on the unshocked, originate fracture strength plays a more important role in reducing the observed $\Delta T_{\mathrm{c}}$ value than that on the heat transfer conditions in thermal shock.

An approximate equation relating specimen size to initial strength $\left(\sigma_{\mathrm{f}}\right)$ and retained strength $\left(\sigma_{\mathrm{r}}\right)$ after crack propagation caused by thermal shock is given by ${ }^{2)}$

$$
\sigma_{\mathrm{r}}=C /\left(\sigma_{\mathrm{f}}^{1 / 2} a^{1 / 4}\right)
$$

where $C$ is constant for a given material and testing condition. This equation predicts that $\sigma_{\mathrm{r}}$ is an inverse function of the initial strength of the material $\left(\sigma_{\mathrm{f}}\right)$ and the specimen size. However, a size effect in the test for initiate fracture strength will probably also be superposed on the size effect on crack propagation in thermal shock. A new equation is thus proposed to include this effect by merging Eq. (8) with Eq. (5)

$$
\sigma_{\mathrm{r}}=C /\left(\sigma_{0}^{1 / 2} S^{-1 / 2 m}\left(\frac{1}{m} !\right){ }^{1 / 2} a^{1 / 4}\right)=C^{\prime} S^{1 / 2 m} a^{-1 / 4}
$$

where $C^{\prime}$ is constant. This equation indicates that increasing the specimen size will increase the value of the term $\left(S^{1 / 2 m}\right)$ but reduce that of the term $\left(a^{-1 / 4}\right)$. Therefore, the size sensitivity of the retained strength after thermal shock will depend on which term dominate for a given condition. The effect of specimen size on the retained strength after thermal shock testing in the current study can now be examined by applying Eq. (9).

The Weibull modulus must be determined before applying Eq. (9). As more specimens were used in the test of initial fracture strength for large specimens (fifteen pieces) than small specimens (ten pieces), a Weibull plot of the flexural strength data of large specimens was exerted as shown in Fig. 8. The Weibull modulus, $m$, was determined as 11 from the slope of the straight line shown in Fig. 8. The retained strengths at $\Delta T_{\mathrm{c}}$ for small and large specimens were determined as 130 and $95 \mathrm{MPa}$, respectively, by using the data points dropping from the initial fracture strength lines as shown in Figs. 1 and 2. As the load span in the flexural strength test for small and large specimens are identical, the effective stressed area $(S)$ ratio of large specimen over small specimen is equal to three so as the ratio of the characteristic length, $a$. With the values of these terms determined, the expected $\sigma_{\mathrm{r}}$ value for the small specimens can thus be obtained from Eq. (9) based on the observed $\sigma_{\mathrm{r}}$ value of large specimen. The calculated $\sigma_{\mathrm{r}}$ value for small specimen is $119 \mathrm{MPa}$, which, in view of the scatter in the data, agrees reasonably well with the observed value 130 $\mathrm{MPa}$. As a result, the size effect on the retained strength after thermal shock should be evaluated including the size

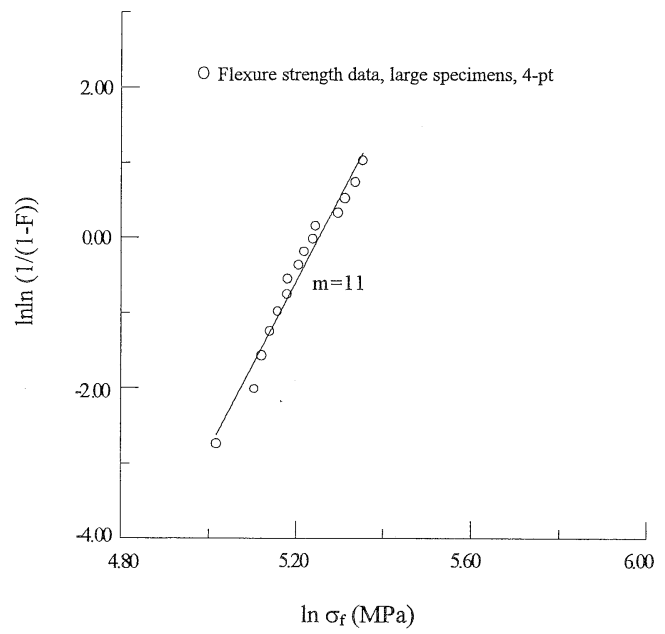

Fig. 8. Weibull plot of unshocked fracture strength for large specimens.

effect on the initial fracture strength such as proposed in Eq. (9).

\section{Summary and conclusions}

(1) The observed strength degradation behavior of an alumina in two sizes subjected to thermal shock loading agrees with the thermal shock theory for ceramics developed by Hasselman.

(2) $\Delta T_{\mathrm{c}}$ values for the large and small specimens were found to be 175 and $200^{\circ} \mathrm{C}$, respectively. The reduction in thermal resistance with increasing sample size can be well described by the thermal elastic and fracture energy theories.

(3) If the size effect on the flexural strength of as-received, unshocked specimen is considered, the size effect on the transport of heat during quench test might play a less important role in reducing the thermal shock resistance of large specimen. Therefore, studying the effect of specimen size on thermal shock resistance of ceramics should include consideration of the size effect on mechanical strength in addition to the influence of specimen size on heat transfer rate.

(4) The existence of transverse cracks was responsible for the reduction of flexural strength in quenched bend-bar subjected to thermal shock loading with $\Delta T \geqq \Delta T_{\text {c }}$.

\section{References}

1) D. P. H. Hasselman, J. Am. Ceram. Soc., 52, 600-04 (1969).

2) D. P. H. Hasselman, J. Am. Ceram. Soc., 53, 490-95 (1970).

3) T. K. Gupta, J. Am. Ceram. Soc., 55, 249-53 (1972).

4) T. K. Gupta, J. Am. Ceram. Soc., 58, 158-59 (1975).

5) P. F. Becher, D. Lews III, K. C. Karman and A. C. Gonzalez, Am. Ceram. Soc. Bull., 59, 542-48 (1980).

6) P.F. Becher and W. H. Warwick, "Thermal Shock and Thermal Fatigue Behavior of Advanced Ceramics," Ed. by G. A. Schneider and G. Petzow, Kluwer Academic, The Netherlands (1993) pp. 37-48.

7) "Thermal Shock and Thermal Fatigue Behavior of Advanced Ceramics," Ed. by G. A. Schneider and G. Petzow, Kluwer Academic, The Netherlands (1993).

8) E. H. Lutz, J. Am. Ceram. Soc., 78, 2700-04 (1995).

9) E. Glenny and M. G. Royston, Trans. Br. Ceram. Soc., 57 , 645-77 (1958)

10) R. W. Davidge and G. Tappin, Trans. Br. Ceram. Soc., 66, 405-22 (1967)

11) D. G. S. Davies, Proc. Br. Ceram. Soc., 22, 429-52 (1973). 